assess other important obstetric outcomes, e.g. hypertensive disorders of pregnancy.

\section{RF18 CONTRIBUTION OF SEVERE NEONATAL MORBIDITY TO NEURODEVELOPMENT AT 2 YEARS OF AGE AMONG VERY PRETERM INFANTS: A MEDIATION ANALYSIS}

${ }^{1} \mathrm{C}$ Bonnet, ${ }^{2} \mathrm{ES}$ Draper, ${ }^{3} \mathrm{RF}$ Maier, ${ }^{4} \mathrm{M}$ Cuttini, ${ }^{4} \mathrm{~L}$ Herich, ${ }^{2} \mathrm{~S} J$ Johnson, ${ }^{1} \mathrm{~J}$ Zeitlin*. 'Obstetrical, Perinatal and Pediatric Epidemiology Research Team, Inserm, Paris, France; ${ }^{2}$ Department of Health Sciences, Leicester University, Leicester, UK; ${ }^{3}$ Children's Hospital, Marburg Univeristy, Marburg, Germany; ${ }^{4}$ Clinical Care and Management Innovation Research Area, Bambino Gesù Children's Hospital, Rome, Italy

\subsection{6/jech-2019-SSMabstracts. 133}

Background Low gestational age (GA) is the principle risk factor for poor long-term neurodevelopment among very preterm (VPT) children. Some of this effect results from a greater vulnerability to severe neonatal morbidities (SNM) which are strongly related to low GA as well as to poor neurodevelopmental outcome. We aimed to investigate how SNM mediates the relationship between GA and VPT adverse neurodevelopmental outcome at 2 years of corrected age.

Methods Data come from the area-based Effective Perinatal Intensive Care in Europe (EPICE) cohort of children born below 32 weeks' GA in 2011/2012 in 11 European countries. Perinatal data were abstracted from medical records and follow-up was conducted using parent questionnaires at 2 years of corrected age. Children unable to walk without assistance or aids, or sit or hold their head up without support were classified with severe gross motor impairment (GMI); Non-verbal cognitive impairment (NVCI) was assessed as a score $<22$ on the non-verbal cognition scale of the Parent Report of Children's Abilities-Revised (PARCA-R) and language impairment (LI) was defined as an expressive vocabulary of less than 10 words. SNM was defined as one or more of the following morbidities: intraventricular hemorrhage grades III \& IV, cystic periventricular leukomalacia, retinopathy of prematurity stages III-V, surgical necrotizing enterocolitis or broncho-pulmonary dysplasia. An inverse odds weighting (IOW) mediation analysis was used to estimate the total effects of GA, and estimated indirect effects operating through SNM or directly through GA. CI were estimated by bootstrapping. Co-variables included perinatal risk factors and family socioeconomic characteristics.

Results Of 3370 children assessed in the follow-up; 5.3\% had GMI, 14.9\% had NVCI and 9.4\% had LI. A one-week increase in GA was associated with a decreased risk of GMI $(\mathrm{OR}=0.80 ; 95 \mathrm{CI} \%=0.74-0.86])$, of NVCI $(\mathrm{OR}=0.85 ; 95 \mathrm{CI}$ $\%=0.81-0.89])$ and $\mathrm{LI} \quad(\mathrm{OR}=0.89 ; 95 \mathrm{CI} \%=0.83-0.96])$. $20.4 \%$ of infants had at least one severe morbidity and this was more common among children with GMI $(66.0 \%$ vs. $18.4 \%)$, NVCI $(38.8 \%$ vs. $17.2 \%)$ and LI (38.4\% vs. $18.4 \%)$. For GMI, almost $100 \%$ of the total effect of GA on GMI was mediated by SNM. This proportion was $70 \%$ for NVCI and $40 \%$ for LI.
Conclusion Reducing SNM could lead to substantial improvements in neurodevelopmental outcomes for VPT children, especially those related to motor development.

\section{Interventions \& Stakeholders' Perspectives}

\section{RF19 IDEOLOGY, STAKEHOLDERS AND PUBLIC HEALTH POLICY: A COMPARISON OF MEDIA DISCOURSES ON ALCOHOL AND SUGAR PRICING POLICY IN THE UK}

${ }^{1} \mathrm{~S}$ Hilton*, ${ }^{2} \mathrm{~T}$ Henrichsen, ${ }^{1} \mathrm{G}$ Fergie, ${ }^{1} \mathrm{CH}$ Buckton, ${ }^{2} \mathrm{P}$ Leifeld. ${ }^{1} \mathrm{MRC} / \mathrm{CSO}$ Social and Public Health Sciences Unit, University of Glasgow, Glasgow, UK; ${ }^{2}$ School of Social and Political Sciences, University of Glasgow, Glasgow, UK

\subsection{6/jech-2019-SSMabstracts. 134}

Background The media are a key influence on public and policymakers' perceptions of the need for, and acceptability of, new policies to improve population health. In the case of Minimum Unit Pricing (MUP) for alcohol and the Soft Drinks Industry Levy (SDIL), previous analysis suggests that an actor's position in the network is linked to their ideology, for example using social vs market justice arguments. In this study we use ideological scaling to examine stakeholders' policy positioning further.

Methods Data sets were generated from public debates on MUP and SDIL in UK newspapers using content analysis and discourse network analysis. Actor statements were analysed using ideological scaling of ideal points in Item Response Theory models. This approach is based on the assumption that actors communicate their ideological position through verbal statements in public documents. These statements then provide the basis to estimate underlying ideological positions of actors in specific policy areas. Ideological positions were estimated using Markov Chain Monte Carlo in the Bayesian Ideal Point model of Martin and Quinn.

Results In both debates, health charity and advocacy groups, individual NHS organisations and professional associations, as well as government advisory bodies, had a clear policy supporting ideology. Contrary to this, manufacturers/associated industries and associations, as well as think tanks and research analysts, had an opposing ideology. For the policy opponents, the most discriminating policy concepts were mainly economic or political in nature (e.g., 'Policy is illegal', 'Policy will damage industry and associated industries', 'Government action on commodity consumption is nanny statist' or 'Policy will damage the wider economy'). For the policy proponents, the most discriminatory policy concepts related to public health issues ('Policy will reduce consumption of commodity', 'Policy needed to address commodity 'problem", 'Policy will improve population health').

Conclusion The media are a key influence on public and policymakers' perceptions of the need for, and acceptability of, new policies to improve population health. In contested public policy debates, stakeholders on both sides of the argument put forward competing rhetoric via the media to support their position in line with their vested interests whether driven by social and market justice principles. 